\title{
Encapsulated Cell Biodelivery of Transposon-Mediated High-Dose NGF to the Göttingen Mini Pig Basal Forebrain
}

\author{
Lone Fjord-Larsen ${ }^{*}, 1$, Philip Kusk ${ }^{1}$, Malene Torp ${ }^{1}$, Jens Christian H. Sørensen², Kaare Ettrup ${ }^{2}$, \\ Carsten R. Bjarkam ${ }^{2}$, Jens Tornøe ${ }^{1}$, Bengt Juliusson ${ }^{1}$ and Lars U. Wahlberg ${ }^{3}$ \\ ${ }^{I}$ NsGene A/S, Baltorpvej 154, DK-2750 Ballerup, Denmark \\ ${ }^{2}$ Department of Neurosurgery, Aarhus University Hospital, DK-8000 Aarhus C, Denmark \\ ${ }^{3}$ NsGene, Inc., 225 Chapman St., Providence, RI 02905, USA
}

\begin{abstract}
Nerve Growth Factor (NGF) has therapeutic effects on the cholinergic neurodegeneration in Alzheimer's disease (AD). We have previously described an implantable Encapsulated Cell Biodelivery ${ }^{\mathrm{TM}}$ device, NsG0202, capable of local delivery of NGF to the human cholinergic basal forebrain. Results from a small Phase $1 \mathrm{~b}$ clinical study showed that the NGF dose could advantageously be increased. We have therefore developed a second generation clinical device named NsG0202.1, containing an RPE cell line (NGC0211) generated with transposon expression technology for highdose NGF production. Furthermore, to promote cell attachment and long-term viability of NGC0211, a polyethylene terephthalate (PET) yarn scaffolding was used. The safety was tested in Göttingen minipigs during a six months period with NsG0202.1 implants placed in the basal forebrain. The devices were well tolerated and the NGC0211 viability and NGF secretion remained after 6 months in vivo. The NGF induced relevant biological responses in the surrounding cholinergic target neurons.
\end{abstract}

Keywords: Encapsulated Cell Biodelivery ${ }^{\mathrm{TM}}$, Göttingen minipigs, preclinical testing, Nerve Growth Factor, Alzheimer's Disease, Sleeping Beauty, transposon.

\section{INTRODUCTION}

According to the World Alzheimer Report 2010 from Alzheimer's disease International, it is estimated that around 35.6 million of the population worldwide suffer from dementia. The most common cause of dementia is Alzheimer's disease (AD). The etiology of the disease remains elusive, but AD brains are characterized by three primary histological features: amyloid plaques, neurofibrillary tangles and severe cholinergic neuronal death occurring in the nucleus basalis of Meynert of the basal forebrain (see reviews [1, 2]). At present no disease-modifying therapy is available. Pharmacological improvement of cholinergic function can stabilize cognition and memory function in patients with early $\mathrm{AD}$ for up to 12 months, but the therapeutic effects are modest and transient [3-5]. Nerve Growth Factor (NGF) has therapeutic potential as a symptomatic and disease-modifying agent capable of regenerating dying cholinergic neurons and preventing the progressive cholinergic degeneration associated with the cognitive decline in AD. NGF does not readily cross the blood-brain barrier and is associated with painful side effects when administered systemically and must therefore be delivered directly to the brain in order to achieve a therapeutic window. Furthermore, NGF delivery to the vicinity of the cholinergic cell bodies is preferred, as impaired endogenous transport of NGF from the cholinergic terminals

*Address correspondence to this author at the NsGene A/S, Baltorpvej 154, DK-2750 Ballerup, Denmark; Tel: +45 4460 8900; Fax: +45 4460 8989; E-mails: lone.fjordlarsen@gmail.com,luw@nsgene.com to the cholinergic neurons is implicated in the AD pathology [6]. Encapsulated Cell (EC) Biodelivery ${ }^{\mathrm{TM}}$ provides a method for safe and sustained delivery of NGF directly to the anatomical target. The delivery platform combines the potency of de novo synthesis of the therapeutic protein in situ with the safety of an implantable and retrievable medical device [7].

We have previously described a clinically applicable NGF-secreting EC Biodelivery ${ }^{\mathrm{TM}}$ implant $(\mathrm{NsG0202)}$ that can be safely implanted in the brain, retrieved, and show long-term function [8]. The NsG0202 implant has also been tested in an initial Phase $1 \mathrm{~b}$ clinical study to examine the safety of devices implanted in the basal forebrain (nucleus basalis of Meynert) of patients with mild to moderate $\mathrm{AD}$ (Eriksdotter-Jönhagen et al.; Wahlberg et al., manuscripts submitted). The successful safety profile in all patients and relevant improvement in cognition and biomarkers in some patients, suggest that a dose escalation step is relevant. To accomplish higher secretion, we generated clonal NGFsecreting human ARPE-19 cell lines using the Sleeping Beauty transposon system [9]. The optimized SB transposase (SB100x) mediates genomic integration of multiple copies of the transgene inserted between two transposon terminal inverted repeats, resulting in stable gene transfer with longterm gene expression, comparable with the efficacy of viral gene transfer systems [10]. From the resulting clones, we selected NGC0211, which showed optimal survival in devices and about a 10-fold increase in NGF expression and corresponding improved in vivo potency [11]. 
In the present study, the NGC0211 cells was used in $2^{\text {nd }}$ generation clinical devices, where the polyvinylalcohol (PVA) foam scaffold was replaced with a polyethylene terephthalate (PET) yarn matrix. The PET yarn is biocompatible and has excellent cell attachment properties. In addition to improving cell viability, the change of scaffold rendered the manufacture of the devices more reproducible.

In the present study, the long-term function and safety of the improved clinical devices, named NsG0202.1, were evaluated six months after implantation in Göttingen minipigs. It was envisioned that the study should mimic the clinical situation as much as possible to enable clinical translation. The clinical sized devices, with a flexible tether for device anchoring and retrieval linked to the active part, were stereotaxically implanted in each side of the basal forebrain. The function and integrity of the NsG0202.1 devices were evaluated by histological examinations and measurement of NGF release. NGF diffusion in tissue and the effect on cholinergic target neurons were assessed by analyses of immunohistochemical stainings. Toxicity was evaluated by histopathological examination of the local tissue reaction of the NsG0202.1 implants, blood analyses and observation of the general behavior of the minipigs.

\section{MATERIALS AND METHODS}

\section{Production of NsG0202.1 Devices}

A polyurethane tether (Lubrizol, USA) was attached to an $11 \mathrm{~mm}$ long Polyether sulfone (PES) membrane (Akzo Membrana, Obernburg, Germany) via a titanium linker. The tether-linker-membrane junction was secured with UV-cured acrylic-based glue and the membrane void was fitted with a matrix of PET yarn (J.L. Corporation, Greenville, USA). Prior to filling, cells were cultured and dissociated, as previously described [8]. A total seed of $10^{5}$ NGC0211 cells were injected into each device. After filling, devices were kept in human endothelial serum-free medium (HE-SFM, Invitrogen, DK) at $37^{\circ} \mathrm{C}$ and $5 \% \mathrm{CO}_{2}$ for 4.5 weeks for sterility, mycoplasma and expression level tests, before release for implantation.

\section{NGF ELISA}

The amount of NGF released by each capsule over a 4 hour incubation period in $1 \mathrm{ml}$ of HE-SFM was measured using NGF sandwich ELISA (R\&D Systems, Arbingdon, UK). Standards and samples were assayed in duplicate according to manufacturer's instructions. Results were expressed in ng NGF per 24 hours.

\section{Evaluation of Cell Survival in Devices}

Devices were fixed in 4\% Formalin solution, dehydrated in graded ethanol series and embedded in historesin (Leica Microsystems, Ballerup, DK). Sections $(5 \mu \mathrm{m})$ were mounted on poly-l-lysine coated slides and stained with Haematoxylin-Eosin (Bie \& Berntsen, Rødovre, DK). Cellular content and morphology were analysed using light microscopy.

\section{Animals}

All work involving animals was conducted in accordance with the Danish Animal Protection Law and with experi- mental procedures approved by the Danish National Committee for Ethics in Animal Research. Five female Göttingen minipigs (Ellegaard Göttingen Minipigs ApS, DK), weighing $7.8 \pm 0.2 \mathrm{~kg}$ at the start of the experiment, were implanted with the clinical NsG0202.1 devices. Three untreated pigs were included in the study as controls (mean weight $8 \pm 0 \mathrm{~kg}$ ). The pigs were housed in standard pig pens in an animal room provided with filtered air at a temperature of $21^{\circ} \mathrm{C} \pm$ $3{ }^{\circ} \mathrm{C}$, a relative humidity of $55 \% \pm 15 \%$ and a standardized $12 \mathrm{~h} \mathrm{light/dark} \mathrm{cycle.} \mathrm{Pigs} \mathrm{were} \mathrm{routinely} \mathrm{fed} \mathrm{with} 10 \mathrm{~g}$ per $\mathrm{kg}$ animal twice a day of "Mini-Pig Expanded" (Special Diet Services, Witham, UK), with the amount of diet occasionally being adjusted in order to allow a reasonable growth. Throughout the study, the status of the animals was checked daily by experienced staff. Animal health, based on observation of the individual animals, was evaluated by a veterinarian on a monthly basis. Blood chemistry analyses on samples taken before implantations and at the time of explantation were performed as previously described [8]. Serum samples (taken before implantations and at the time of explantation) and CSF samples (taken at the time of explantation) were tested in the NGF ELISA (detection limit $30 \mathrm{pg} \mathrm{NGF/ml} \mathrm{serum} \mathrm{or} \mathrm{CSF).}$

\section{Implantation and Explantation of NsG0202.1 Devices}

Animals were sedated for surgery and maintained on assisted ventilation. A stereotaxic MRI scan was carried out using a Signa HDx 3T.0 scanner (General Electric, USA) prior to bilateral stereotaxic implantation [12] of two NsG0202.1 devices in each side of the basal forebrain with stereotaxic coordinates as previously described [8], resulting in a total of four devices per animal. The tethers were cut, so the ends were positioned below the dura. The skin was closed with two layers of sutures. After 6 months, the devices were explanted from sedated pigs maintained on assisted ventilation. After device explantations, pigs were injected with $1 \mathrm{ml}$ Heparin $(5000 \mathrm{IE} / \mathrm{ml})$ followed by injection of $10 \mathrm{ml}$ isotonic saline $(0.9 \% \mathrm{NaCl})$. The animals were then euthanized with Pentobarbital, followed by transcardial perfusion with 3-5 liters of $0.9 \% \mathrm{NaCl}$ and 5 liters of $4 \%$ Formalin in $0.15 \mathrm{M}$ phosphate buffer, $\mathrm{pH}$ 7.4. Brains were immediately dissected free of the cranium, embedded in Cavex impressional normal set polymer (Cavex Holland BV, Haarlem, the Netherlands) and sliced in $5 \pm 0.5 \mathrm{~mm}$ slabs with orientation perpendicular to the device (horizontal sections) using a HistOtech Quick slicer (HistOtech ApS, Frederiksberg $\mathrm{C}, \mathrm{DK})$. The alginate was removed, and slabs were post-fixed in 4\% Formalin solution, $\mathrm{pH} 7$ for 1-3 days and then transferred to a $30 \%$ sucrose $/ 0.1 \mathrm{M}$ phosphate buffer for approximately 3-5 days.

\section{Immunohistochemistry}

Frozen minipig brain slabs were cut in six series of $40 \mu \mathrm{m}$ on a freezing microtome. Free-floating sections were quenched of endogenous peroxidase activity through incubation with $3 \% \mathrm{H}_{2} \mathrm{O}_{2}$. Sections were then incubated overnight with goat anti human NGF (R\&D Systems, UK) or mouse antiChAT (Chemicon, DK) antibodies diluted in potassium phosphate-buffered saline containing $2 \%$ normal horse serum and $0.25 \%$ Triton X-100 followed by incubation with the appropriate (anti-mouse or anti-goat) biotinylated 
secondary antibody. This was followed by conjugation of horseradish peroxidase (HRP) using a streptavidin-HRP complex (ABC elite kit, Vector Laboratories, UK), incubation with $\mathrm{DAB}$, and precipitation of the chromophore with $1 \% \mathrm{H}_{2} \mathrm{O}_{2}$. Labeled sections were slide mounted and coverslipped. Whole brain images were prepared using a Hamamatsu Nanozoomer 1.0-HT scanner.

\section{Image Analyses}

Visiomorph software (VisioPharm, Hørsholm, DK) was used to analyze immunostained brain sections. The total NGF-IR area/section around the implant was quantified (five sections from each implant site) and expressed as mean $\mathrm{mm}^{2} /$ section \pm SEM. The relative size of ChAT-IR neurons was determined in a radius of $2 \mathrm{~mm}$ from the implant as well as $>2 \mathrm{~mm}$ away in a circle of similar size, placed approximately at a distance of $2-4 \mathrm{~mm}$ from the implant. In the untreated control pigs, analyses were performed in the corresponding areas. For each implant or control site, the mean neuron size was determined in four serial sections. Data are expressed as the mean size around the implants ( $\mathrm{n}=20$ sites), away from ( $\mathrm{n}=20$ sites) or in the corresponding areas in control pigs ( $\mathrm{n}=24$ sites), expressed as pixels/neuron \pm STDEV

\section{Histopathology}

Areas surrounding the implantation sites were dissected from two $5 \mathrm{~mm}$ slabs per pig. In untreated animals and if the tracks were not visible at the macroscopic level, equivalent areas at the expected track location were dissected. Tissue blocks were sent to a contract laboratory (Harlan Laboratories, Switzerland) where they were paraffin-embedded, sectioned and stained with Haematoxylin-Eosin. This was followed by an evaluation and scoring of the local tissue reactions at AnaPath $\mathrm{GmbH}$, Switzerland. Severity scores were from 1-5, with 1 being minimal and 5 being severe histological changes. A score of 0 was given, if no changes were found.

\section{Statistics}

Sigma Plot (Systat, USA) was used to analyze the data. The weight development for the NsG0202.1 treated and untreated control group was compared by t-test. The MannWhitney Rank Sum Test was used to compare the groups in cases were the raw data was not normally distributed with the same variances. Difference between the means of neuron size around, away and in control animals was tested by One Way Analysis of Variance, followed by All Pairwise Multiple Comparison Procedures, Student-Newman-Keuls Method with p-values less than 0.05 indicating statistical significance.

\section{RESULTS}

\section{Long-Term Function of NsG0202.1 after Implantation in the Basal Forebrain}

NsG0202.1 devices were implanted using magnetic resonance imaging (MRI) scan and stereotaxic neurosurgical techniques, as previously described [8]. Two devices were placed in each side of the basal forebrain in a total of five pigs. Three untreated pigs were included as references. After six months, the devices were explanted and media samples were immediately collected. After an overnight incubation, an additional sample was collected from each NsG0202.1 device. The two post-explantation samplings are shown in Fig. (1a) together with the pre-implantation release, measured 2 weeks after cell filling $(10.8 \pm 1.8 \mathrm{ng} / 24 \mathrm{~h})$. Mean NGF release in the sampling made on the day of explantations was $73.7 \pm 20.3 \mathrm{ng} / 24 \mathrm{~h}$, decreasing to $20.0 \pm 4.3 \mathrm{ng} / 24 \mathrm{~h}$ the day after. For both sampling time points, all devices released measurable NGF, and $95 \%$ (first sampling) or $80 \%$ (second sampling) released $>5 \mathrm{ng} / 24 \mathrm{~h}$.

All explanted devices were intact and without tissue adherence. Histological analysis confirmed that membrane integrity was maintained. In general, the NGC0211 cells showed good survival in vivo (Fig. 1b). However, in some devices a fraction of dead cells without nuclei was observed.
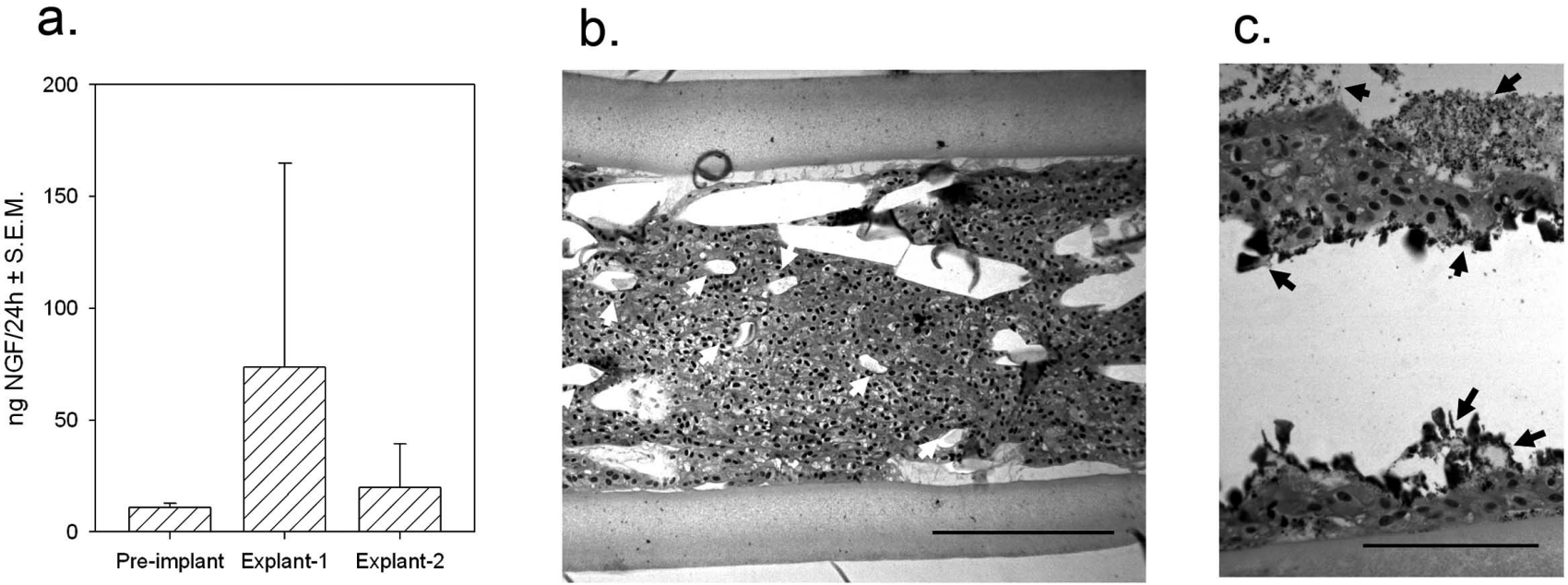

Fig. (1). NsG0202.1 devices after 6 months in the brain. (a) The mean NGF release \pm SEM ( $n=20$ devices) measured from devices before implantation and in two samplings (the same day and the following day) after explantation. (b) Hematoxylin-Eosin staining of a representative explanted NsG0202.1 device showing healthy living cells with dark nuclei. PET yarn scaffold is indicated by white arrows. Scale bar: $300 \mu \mathrm{m}$. (c) NsG0202.1 device with calcified areas (black arrows). The most heavily calcified area (in the middle) was lost during sectioning. Healthy NGC0211 cells are observed outside the calcified areas. Scale bar $=150 \mu \mathrm{m}$. 
Four devices (\#20, 24, 34 and 36) contained only few living cells, correlating with decreased NGF release after explantation (data not shown). Most of the devices contained deposits consistent with calcifications (Fig. 1c). The extent of calcifications was variable throughout the device and also between individual devices. Healthy looking cells were observed outside the dense calcified areas, but as the most affected calcified areas were sheared and lost during sectioning (Fig. 1c), a full evaluation of the cell survival was not possible in these devices. Three of four devices with suboptimal cell survival did not contain calcified areas (data not shown), so metabolic processes from living cells appear to accelerate the mineralization, in accordance with previous observations [13]. However, some mineralization was seen in the fourth device, indicating that the timing of cell death was different in this device. The calcium particles did not affect the integrity of the devices while placed in the brain or at the retrieval.

\section{NGF Diffusion in the Target Area}

Specific diffuse NGF immunoreactivity was detected around the implant sites. NGF-immunoreactive (IR) neurons
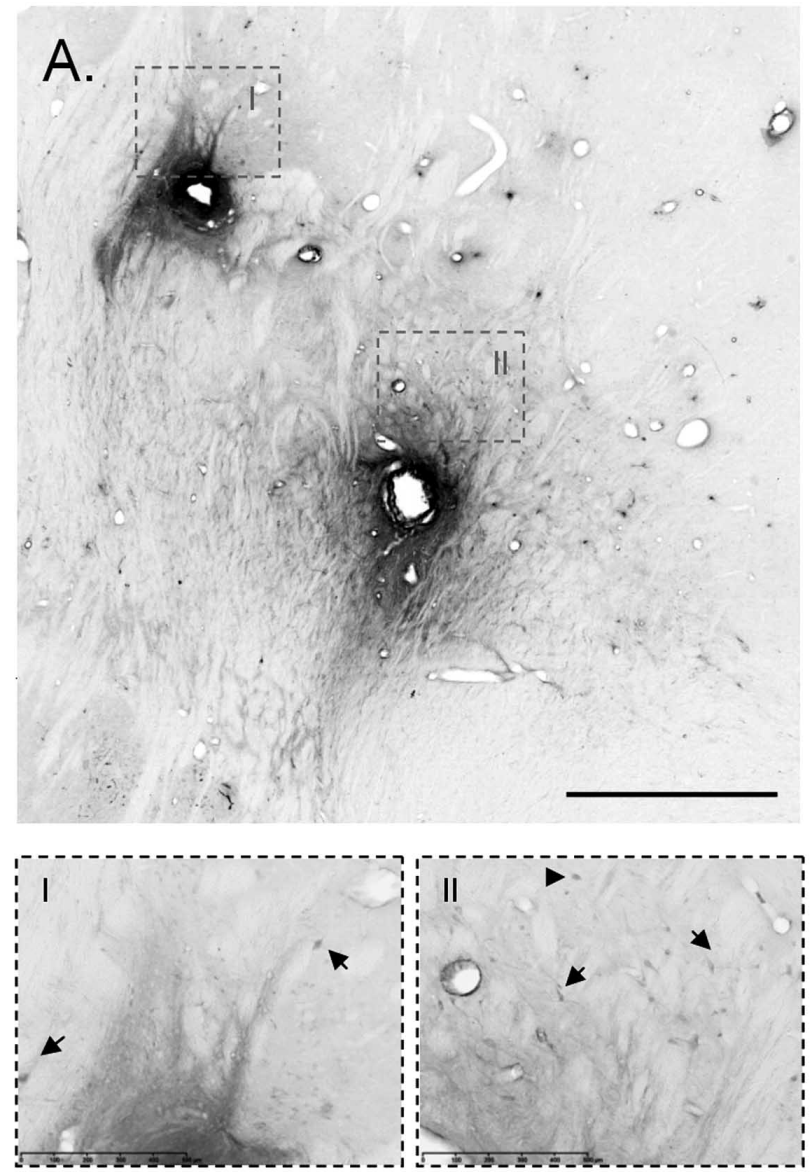

were observed close to the implant sites, indicating that these cells had internalized NGF secreted from the devices (Fig. 2a). The mean NGF-IR area/section for each implant site is shown in Fig. (2b). Note that these values are not absolute, but dependent on the detection threshold for the NGF immunohistochemistry method as well as the configuration used for image analysis. The mean NGF-IR area around implants was $0.73 \pm 0.11 \mathrm{~mm}^{2} / \mathrm{section}$. In addition, the maximal diffusion distance of detectable NGF-immunoreactive signal from the edge of each implant site was determined. Visible radial NGF diffusion distance from the implant sites was up to $2.5 \mathrm{~mm}$ (Fig. 2c).

\section{Bioactivity of Secreted NGF}

Device placement in the target area was satisfying, with cholinergic cells observed in the vicinity of the NsG0202.1 devices. The only exception was the implant site for device $\# 16$, which could not be identified, likely due to a placement outside the dissected target area. NGF has previously been shown to increase the size of cholinergic neurons $[14,15]$. The relative mean size of ChAT-IR neurons was therefore quantified inside a radius of $2 \mathrm{~mm}$ from the implant edge as
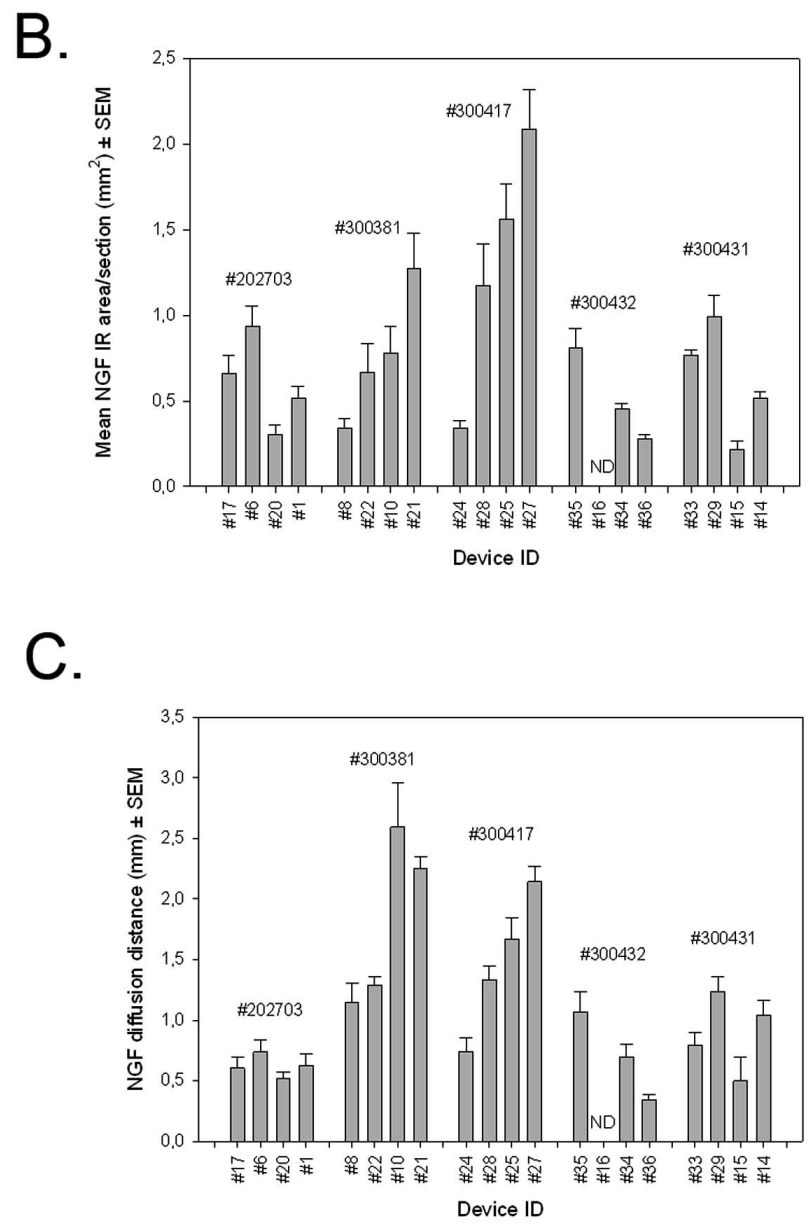

Fig. (2). NGF release from devices in vivo. (a) NGF immunohistochemistry showing NGF release from devices \#25 and \#27. Scale bar = 2 mm. NGF-immunoreactive (IR) cells are indicated by black arrows in insert I and II below. Scale bars $=500 \mu \mathrm{m}$. (b) Quantification of the mean NGF-IR area around individual implant sites, sorted in groups of four devices according to the placement in the pigs (Pig ID numbers are indicated). Data are shown as mean area/section \pm SEM, $n=5$ sections per implant. The NGF-IR area around device \#16 was not determined (ND), as it was not possible due to placement outside the sectioned target area. (c) The maximal diffusion distance of detectable NGF-immunoreactive signal from each implant, listed in the same order, $\mathrm{n}=5$ sections per implant. 
well as in a distance of more than $2 \mathrm{~mm}$ from the implant (Fig. 3a). The size of ChAT-IR neurons in the same areas from the untreated control pigs was also determined. Fig. (3b) shows that the size of ChAT-IR neurons around
NsG0202.1 devices was significantly larger than those more than $2 \mathrm{~mm}$ away or from untreated pigs $(\mathrm{P}<0.05)$. No increase in cholinergic sprouting was observed around the NsG0202.1 devices (data not shown).

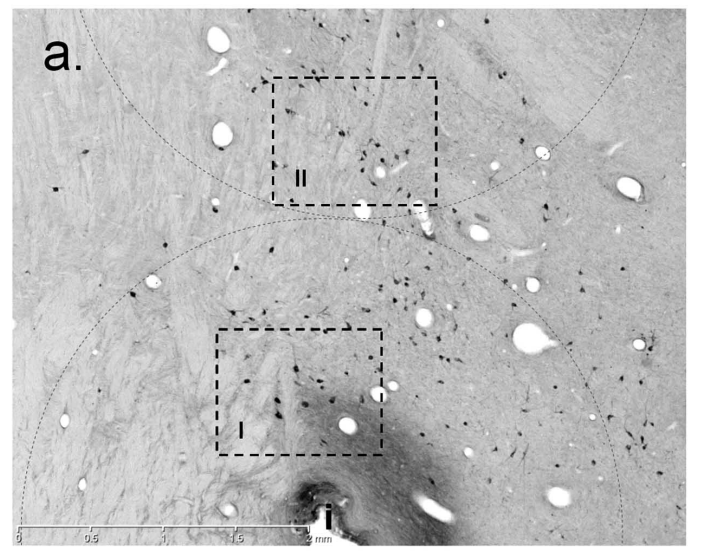

b.
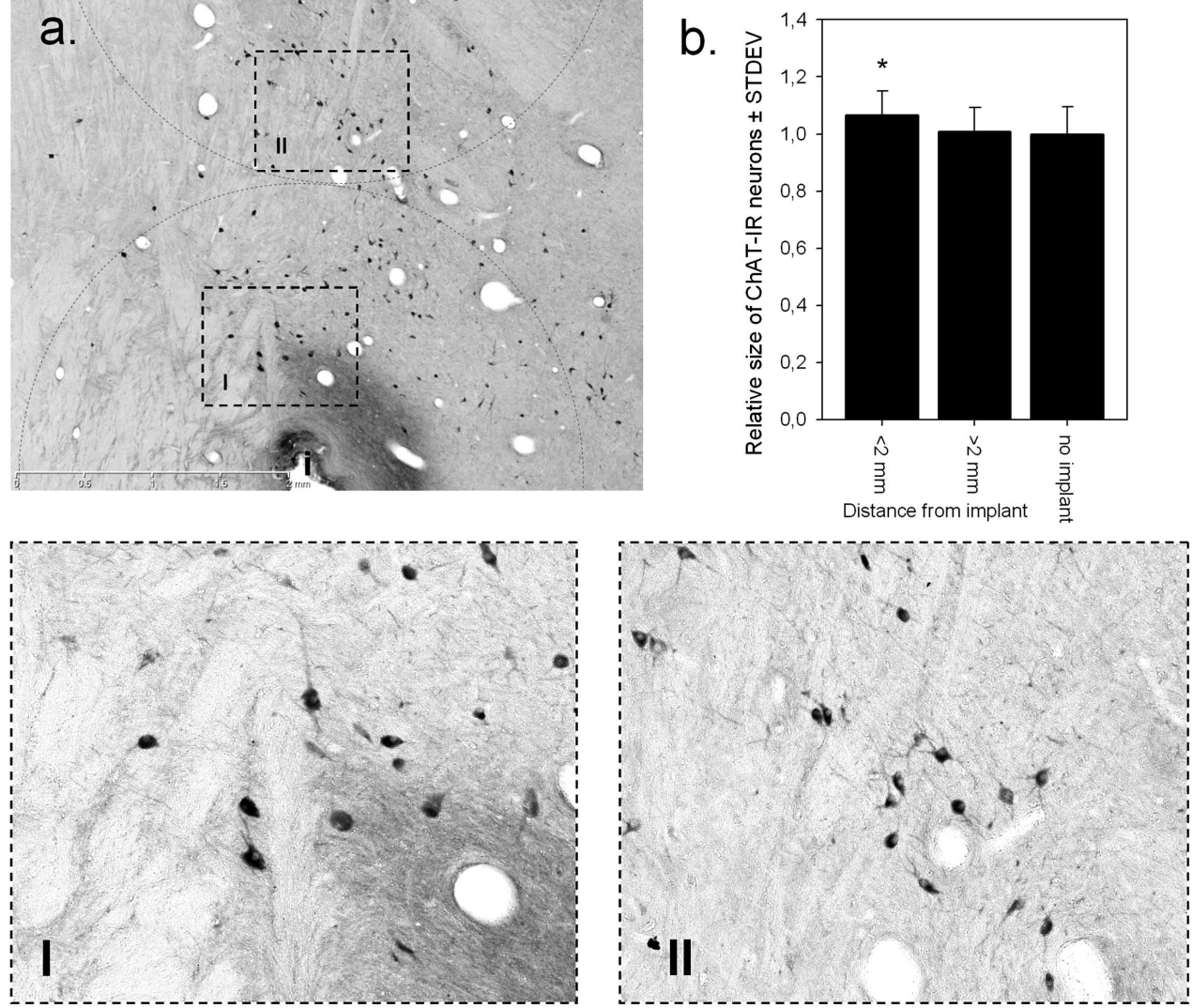

Fig. (3). Effect of secreted NGF on the size of cholinergic neurons. (a) ChAT immunohistochemistry showing cholinergic neurons (ChATpositive) around implant site. Radius and scale bar $=2 \mathrm{~mm}$. Insert I shows ChAT positive neurons inside the $2 \mathrm{~mm}$ radius and insert II outside. Larger ChAT-positive neurons are found in insert I. Scale bar $=300 \mu \mathrm{m}$. (b) Quantification of the mean size of ChAT-IR neurons within a radius of $2 \mathrm{~mm}$ from the NsG0202.1 implant edge, more than $2 \mathrm{~mm}$ away (approximately 2-4 mm) from the implant site, as well as in untreated control animals. The * indicates a significant difference in the mean size of ChAT-IR neurons in a radius $<2$ mm around NsG0202.1 devices compared with $>2 \mathrm{~mm}$ away and in untreated $(\mathrm{P}<0.05)$.
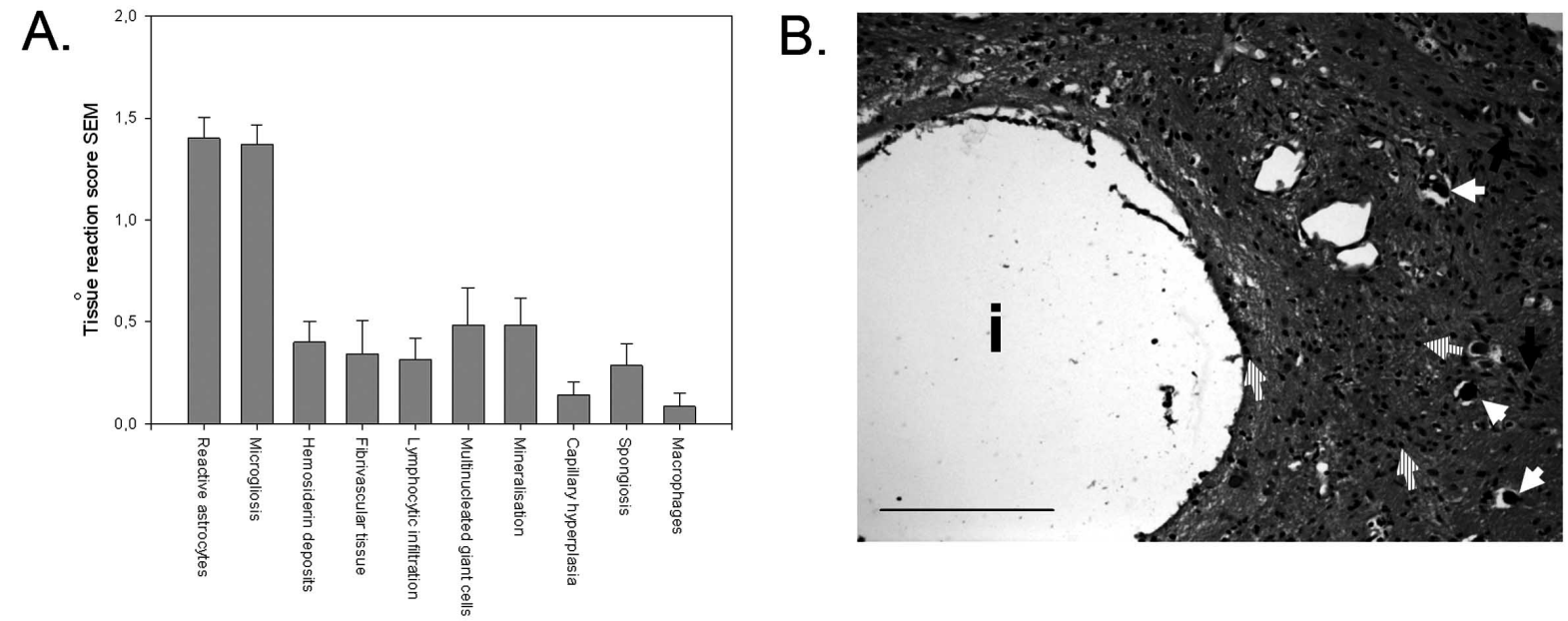

Fig. (4). Evaluation of tissue reactions around implant sites. (a) Tissue reaction scores for histopathological findings in the NsG0202.1 treated pigs. Data are shown as the mean tissue reaction score \pm SEM, $n=5$ pigs. (b) Hematoxylin-eosin staining of a representative implant site (i). The cell reaction in the marginal zone of the shown implant consists of reactive astrocytes, grade 1 (large pale nuclei, striped arrow), microgliosis, grade 2 (dark elongated nuclei, black arrow) and mineralization, grade 2 (dark angular structures, white arrows). Scale bar $=$ $200 \mu \mathrm{m}$. 


\section{Histopathology}

The tissue reaction around the implant sites was relatively mild and consisted mainly of reactive astrocytes and microgliosis (Figs. 4a, b). The size of the reactive zone around the NsG0202.1 devices varied from 50-400 $\mu \mathrm{m}$. In a number of cases some fibrovascular tissue and / or multinucleated giant cells were observed. No histopathological changes were found in the untreated control animals.

\section{Animal Health}

The pigs were observed daily throughout the test period for any adverse effects. Inspection by veterinarian as well as weight measurements was carried out with monthly intervals (Fig. 5). At three months after implantations, the control group had a significantly smaller weight than the NsG0202.1 treated pigs $(\mathrm{P}=0,038)$. This observation could be explained by the fact that the pigs in the control group suffered from diarrhea prior to this weight measurement, and the higher weight is therefore unlikely to be related to the NsG0202.1 treatment. For all other time points in the experimental period, there was no statistical difference in the mean weight of the NsG0202.1 treated group and the untreated control $(\mathrm{P}>0.05)$.

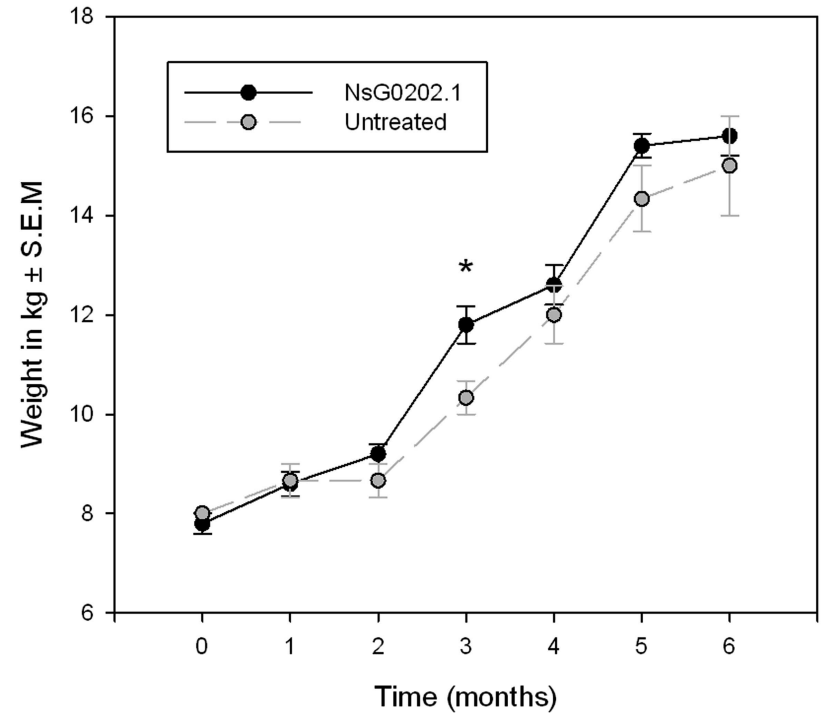

Fig. (5). Weight curves of Göttingen minipigs in the NsG0202.1 treated group $(\mathrm{n}=5)$ and untreated control group $(\mathrm{n}=3)$. Data are shown as the mean weight \pm S.E.M. and * indicates a significant difference $(\mathrm{P}=0,038)$ between the two treatment groups, likely caused by diarrhea in the control group.

Animal health status was also screened by a number of blood tests covering vital organs such as bone marrow, liver and kidneys (data not shown). In addition to the untreated pigs included in the study results were, where possible, compared with clinical chemistry data for untreated Göttingen mini pigs at http://www.minipigs.dk. Tests were within normal limits for all animals and showed no significant difference between treatment groups $(\mathrm{P}>0.05)$.

\section{DISCUSSION}

The EC Biodelivery ${ }^{\mathrm{TM}}$ product NsG0202.1 releasing human NGF was evaluated after six months in the brain. The device integrity was maintained, and no complications were observed during the implantation surgery or the retrieval procedure. There were no signs of toxicity of either the implant or the secreted NGF protein, as evaluated by observation of the general behavior of the minipigs, blood analyses and histopathological examination of the local tissue reaction of the implant. Systemic and intrathecal NGF infusion have been associated with weight loss [16]. In contrast, we found that the mean weight of the NsG0202.1-treated group was not below that of untreated control pigs throughout the 6 months treatment period. The local delivery of NGF in the brain did not result in detectable increases of NGF levels in serum or CSF, and no development of antibodies binding to human NGF was found (data not shown). Importantly, we detected an NGF-induced response of the cholinergic target neurons around the devices. As this effect of NGF is not maintained after discontinuation of the NGF administration $[17,18]$, the result shows that the release of NGF from NsG0202.1 devices continues at a relevant biological level for at least six months.

A specific diffusive NGF-immunoreactive signal was detected around NsG0202.1 devices. The maximal visibly detectable NGF-immunoreactive signal from the edge of each implant site was $2.5 \mathrm{~mm}$, with a mean of $1.12 \pm 0.14$ $\mathrm{mm}$. Though below the detection limit for the NGF immunostaining method, biologically relevant NGF doses are likely to be present at even longer distances from the devices [11]. For a clinical application, the cholinergic target region extends approximately $14 \mathrm{~mm}$ anteriomedially to posteriolaterally [19]. Two implants in each brain hemisphere spaced approximately $7 \mathrm{~mm}$ apart would thus cover most of this anatomical region with biologically relevant doses of NGF.

The four devices with sub-optimal cell survival (\#20, 24, 34 and 36) and the lowest individual explant NGF release (data not shown) did still result in some NGF immunoreactivity around the implant site (Figs. $\mathbf{2 b}, \mathbf{c}$ ). This might be explained by a late time of cell death in the devices during the six months period in the brain and a continuous release of accumulated NGF from the device. The difference between the two post-explantation samplings is likely to reflect an initial wash-out in the culture medium of such NGF accumulation in the devices in vivo (in the unstirred fluid of the membrane and interior device components), as previously described [8].

We observed a marked increase in NGF release from the NsG0202.1 devices, compared with the previously described NsG0202 devices [8]. The NGF tissue levels were determined in an additional pig, sacrificed three days after NsG0202.1 device implantations. Fresh-frozen tissue punches $(2 \mathrm{~mm}$ diameter) were taken around the four implantation sites, and reference punches were taken in cortex and cerebellum. While endogenous NGF levels in cortex and cerebellum were less than $1.5 \mathrm{pg} \mathrm{NGF} / \mathrm{mg}$ tissue, we detected $214 \pm 79 \mathrm{pg} \mathrm{NGF} / \mathrm{mg}$ tissue around the implants. In the previous NsG0202 study with NGC-0295 cells, concentrations of 8.3-20.7 pg NGF/mg tissue were measured around devices seven weeks after implantations [8]. Despite the fact that we cannot directly compare the tissue levels after three days and seven weeks, the result strongly supports that a higher dose is obtained with NsG0202.1 devices. The primary reason for the increased NGF tissue levels around 
NsG0202.1 devices is the exchange of NGC-0295 cells with NGC0211 cells with a 10-fold higher NGF expression. Consistent with this, studies in rat brain have shown a significantly higher NGF release as well as in vivo potency of devices with NGC0211 cells, compared with NGC-0295 cells [11]. We have used the SB transposon technology for transfer of the NGF gene to obtain the NGC0211 cells. The resulting expression level is also at least ten times higher than previously described for NGF-secreting rat fibroblasts used for grafting or encapsulation [20-22]. The enhanced expression may be explained by the insertion of multiple gene copies. In addition, SB transposons seem to more rarely target the inactive heterocromatin regions and the cut and paste mechanism of transposon-mediated gene transfer results in a single copy of the gene per insertion locus, thereby avoiding concatamer-induced gene silencing by heterochromation formation [23].

In addition to using the NGC0211 cell line, the cellsupporting function of the NsG0202.1 devices was improved by the change of scaffold to PET yarn. In cell culture medium, devices with PET yarn and filled with NGC0211 cells released significantly more NGF than the original device configuration with PVA foam matrix (data not shown). The explanation for this might be a better diffusion of nutrients, resulting in increased survival and NGF production.

We have earlier observed calcifications in NsG0202 devices implanted in minipig brain [8]. Calcification of biomaterials such as PVA has previously been demonstrated $[13,24]$ and might explain the previous observed calcifications. However, the calcifications in the present study were somewhat surprising, since another minipig study using a similar device configuration with PET yarn and cells originating from the same parental cell line, did not show any calcifications in devices explanted from brains after six months (unpublished results from our group). The differences between these two studies are the secreted proteins, the encapsulated cell clones, the target areas (basal forebrain versus amygdala and hippocampus) and the age/weight of the pigs at the beginning of the study (7-8 $\mathrm{kg}$ versus 13-16 $\mathrm{kg}$ ). Calcification has in other contexts been shown to be accelerated by young recipient age $[25,26]$, indicating that the age is the most likely explanation for the difference between the studies. In the small phase $1 \mathrm{~b}$ clinical testing of NsG0202 devices in patients with mild to moderate AD no calcifications were observed (Wahlberg et al., submitted manuscript). This result suggests that calcifications in NsG0202.1 devices are not likely to occur when implanted in adult human subjects.

Despite the xenogeneic conditions, the reactive changes in the porcine brain tissue surrounding NsG0202.1 devices were mild and restricted to the site of implantation by a rather narrow marginal zone, and there was no brain damage in remote areas. We have previously shown that the tissue reaction around $\mathrm{NsG0202}$ devices was not significantly different from the reaction around devices without cells or sham surgery sites [8]. However, as the device represents a foreign body, some degree of tissue reaction is unavoidable. Implanted medical devices lead to an acute phase response, followed by a chronic response (see reviews [27, 28]). In the acute phase, inflammatory signals released at the implant site stimulate circulating leukocytes which are subsequently replaced by macrophages and microglia cells. During the healing process, layers of connective tissue and astrocytes are formed around the implant. It appears likely that such capsule formation could influence the survival of the encapsulated cells by restricting the diffusion of nutrients. The observed tissue reaction around device \#34 and \#36 (with suboptimal cell survival) was more prominent than that at other implant sites (data not shown) and could therefore potentially explain the reduced survival. For implanted neural probes, coating with anti-inflammatory drugs reduced the reactivity of microglia and macrophages as well as neuronal loss [29]. This approach might therefore also represent a way to reduce the mild reactive changes around NsG0202.1 implants even more.

The current results from the minipig model shows that the clinical size NsG0202.1 product does not display safety issues. Compared with product NsG0202, the NsG0202.1 product delivers a markedly increased dose of NGF. The present study shows that the dose delivered by NsG0202.1 has significant effect on cholinergic target neurons in the vicinity of the implanted device during a six months period. This is a very promising result for the development of a safe and regenerative therapy against AD. The next step would be a dose-escalation study in $\mathrm{AD}$ patients.

\section{ACKNOWLEDGEMENTS}

The authors wish to thank Hanne Fosmark, Helle Nymark, Marianne Kureer and Juliano Olsen (NsGene A/S) for excellent technical assistance. The technical assistance with mini pigs and surgery procedures by Lise Moberg Fitting and Walther Gyldenløve (Aarhus University Hospital) is also highly appreciated. In addition, Kristina Wikström (Vecura, Karolinska University Hospital, Stockholm, Sweden) is thanked for handling and analysis of clinical NsG0202.1 devices, Susan Gaehler (Harlan Laboratories, Switzerland) for processing of tissue for histopathology and Professor Georg Krinke (AnaPath $\mathrm{GmbH}$, Switzerland) for performing the histopathological evaluation.

\section{CONFLICT OF INTEREST}

Lone Fjord-Larsen, Philip Kusk, Malene Torp, Jens Tornøe, Bengt Juliusson and Lars U Wahlberg are employed by NsGene. This study was funded by NsGene.

\section{REFERENCES}

[1] Citron M. Strategies for disease modification in Alzheimer's disease. Nat Rev Neurosci 2004; 5: 677-85.

[2] Schindowski K, Belarbi K, Buee L. Neurotrophic factors in Alzheimer's disease: role of axonal transport. Genes Brain Behav 2008; 7 (Suppl. 1): 43-56.

[3] Birks J. Cholinesterase inhibitors for Alzheimer's disease. Cochrane Database Syst Rev 2006; 1: CD005593.

[4] O'Brien JT, Burns A. Clinical practice with anti-dementia drugs: a revised (second) consensus statement from the British Association for Psychopharmacology. J Psychopharmacol 2011; 25(8): 9971019.

[5] Hansen RA, Gartlehner G, Lohr KN, Kaufer DI. Functional outcomes of drug treatment in Alzheimer's disease: A systematic review and meta-analysis. Drugs Aging 2007; 24:155-67. 
[6] Salehi A, Delcroix JD, Swaab DF. Alzheimer's disease and NGF signaling. J Neural Transm 2004; 111: 323-45.

[7] Lindvall O, Wahlberg LU. Encapsulated cell biodelivery of GDNF: a novel clinical strategy for neuroprotection and neuroregeneration in Parkinson's disease? Exp Neurol 2008; 209: 82-8.

[8] Fjord-Larsen L, Kusk P, Tornoe J, et al. Long-term delivery of nerve growth factor by encapsulated cell biodelivery in the Gottingen minipig basal forebrain. Mol Ther 2010; 18: 2164-72.

[9] Ivics Z, Hackett PB, Plasterk RH, Izsvak Z. Molecular reconstruction of Sleeping Beauty, a Tc1-like transposon from fish, and its transposition in human cells. Cell 1997; 91: 501-10.

[10] Ivics Z, Izsvak Z. The expanding universe of transposon technologies for gene and cell engineering. Mob DNA 2010; 1: 25.

[11] Fjord-Larsen L, Kusk P, Emerich DF, et al. Increased encapsulated cell biodelivery of nerve growth factor in the brain by transposonmediated gene transfer. Gene Ther 2011; doi: 10.1038/gt.2011.178.

[12] Bjarkam CR, Cancian G, Glud AN, Ettrup KS, Jorgensen RL, Sorensen JC. MRI-guided stereotaxic targeting in pigs based on a stereotaxic localizer box fitted with an isocentric frame and use of SurgiPlan computer-planning software. J Neurosci Methods 2009; 183: $119-26$

[13] Schwenter F, Bouche N, Pralong WF, Aebischer P. In vivo calcium deposition on polyvinyl alcohol matrix used in hollow fiber cell macroencapsulation devices. Biomaterials 2004; 25: 3861-8.

[14] Kordower JH, Chen EY, Mufson EJ, Winn SR, Emerich DF. Intrastriatal implants of polymer encapsulated cells genetically modified to secrete human nerve growth factor: trophic effects upon cholinergic and noncholinergic striatal neurons. Neuroscience 1996; 72: 63-77.

[15] Klein RL, Hirko AC, Meyers CA, Grimes JR, Muzyczka N, Meyer EM. NGF gene transfer to intrinsic basal forebrain neurons increases cholinergic cell size and protects from age-related, spatial memory deficits in middle-aged rats. Brain Res 2000; 875: 144-51.

[16] Jonhagen ME. Nerve growth factor treatment in dementia. Alzheimer Dis Assoc Disord 2000; 14 (Suppl. 1): S31-8.

[17] Montero CN, Hefti F. Rescue of lesioned septal cholinergic neurons by nerve growth factor: specificity and requirement for chronic treatment. J Neurosci 1988; 8: 2986-99.
[18] Niewiadomska G, Komorowski S, Baksalerska-Pazera M. Amelioration of cholinergic neurons dysfunction in aged rats depends on the continuous supply of NGF. Neurobiol Aging 2002; 23: 601-13.

[19] Mai JK, Paxinos G, Voss T. Atlas of the human brain. $3^{\text {rd }}$ ed. USA: Academic Press, Elsevier 2008.

[20] Frim DM, Uhler TA, Short MP, et al. Effects of biologically delivered NGF, BDNF and bFGF on striatal excitotoxic lesions. Neuroreport 1993; 4: 367-70.

[21] Hoffman D, Breakefield XO, Short MP, Aebischer P. Transplantation of a polymer-encapsulated cell line genetically engineered to release NGF. Exp Neurol 1993; 122: 100-6.

[22] Conner JM, Darracq MA, Roberts J, Tuszynski MH. Nontropic actions of neurotrophins: subcortical nerve growth factor gene delivery reverses age-related degeneration of primate cortical cholinergic innervation. Proc Natl Acad Sci USA 2001; 98: 1941-6.

[23] Grabundzija I, Irgang M, Mates L, et al. Comparative analysis of transposable element vector systems in human cells. Mol Ther 2010; 18: 1200-9.

[24] Hill DJ, Whittaker AK. Mineralization of radiation-crosslinked polyvinyl alcohol/polyvinyl pyrrolidone hydrogels. J Biomed Mater Res A 2007; 83: 354-61.

[25] Zhang H, Lewis CG, Aronow MS, Gronowicz GA. The effects of patient age on human osteoblasts' response to Ti-6Al-4V implants in vitro. J Orthop Res 2004; 22: 30-8.

[26] Daamen WF, Nillesen ST, Hafmans T, Veerkamp JH, van Luyn MJ, Van Kuppevelt TH. Tissue response of defined collagenelastin scaffolds in young and adult rats with special attention to calcification. Biomaterials 2005; 26: 81-92.

[27] Fournier E, Passirani C, Montero-Menei CN, Benoit JP. Biocompatibility of implantable synthetic polymeric drug carriers: focus on brain biocompatibility. Biomaterials 2003; 24: 3311-31.

[28] Bridges AW, Garcia AJ. Anti-inflammatory polymeric coatings for implantable biomaterials and devices. J Diabetes Sci Technol 2008; 2: 984-94.

[29] Zhong Y, Bellamkonda RV. Dexamethasone-coated neural probes elicit attenuated inflammatory response and neuronal loss compared to uncoated neural probes. Brain Res 2007; 1148: 15-27.

Received: February 07, 2012

Revised: March 20, 2012

Accepted: April 13, 2012

(C) Fjord-Larsen et al.; Licensee Bentham Open.

This is an open access article licensed under the terms of the Creative Commons Attribution Non-Commercial License (http://creativecommons.org/licenses/by$\mathrm{nc} / 3.0 /$ ), which permits unrestricted, non-commercial use, distribution and reproduction in any medium, provided the work is properly cited. 